\title{
BMJ Open Association between community deprivation and practising health behaviours among South Korean adults: a survey-based cross-sectional study
}

\author{
Bich Na Jang (D , ${ }^{1}$ Hin Moi Youn, ${ }^{1}$ Doo Woong Lee, ${ }^{1}$ Jae Hong Joo, ${ }^{1}$ \\ Eun-Cheol Park (i) ${ }^{2}$
}

To cite: Jang BN, Youn HM, Lee DW, et al. Association between community deprivation and practising health behaviours among South Korean adults: a survey-based crosssectional study. BMJ Open 2021;11:e047244. doi:10.1136/ bmjopen-2020-047244

- Prepublication history and supplemental material for this paper is available online. To view these files, please visit the journal online (http://dx.doi. org/10.1136/bmjopen-2020047244).

Received 27 November 2020 Accepted 08 June 2021

Check for updates

(c) Author(s) (or their employer(s)) 2021. Re-use permitted under CC BY-NC. No commercial re-use. See rights and permissions. Published by BMJ.

${ }^{1}$ Department of Public Health, Yonsei University Graduate

School, Seodaemun-gu, Korea (the Republic of)

${ }^{2}$ Department of Preventive

Medicine and Institute of Health Services Research, Yonsei

University College of Medicine, Seodaemun-gu, Korea (the Republic of)

Correspondence to

Dr Eun-Cheol Park;

ecpark@yuhs.ac

\section{ABSTRACT}

Objectives This study aimed to determine the association between community deprivation and poor health behaviours among South Korean adults.

Design This was a survey-based cross-sectional study. Setting and participants Data of 224552 participants from 244 communities were collected from the Korea Community Health Survey, conducted in 2015.

Primary and secondary outcome measures We defined health behaviours by combining three variables: not smoking, not high-risk drinking and walking frequently. Community deprivation was classified into social and economic deprivation.

Results Multilevel logistic analysis was conducted to determine the association of poor health behaviours through a hierarchical model (individual and community) for the 224552 participants. Among them, $69.9 \%$ did not practice healthy behaviours. We found that a higher level of deprivation index was significantly associated with higher odds of not-practising healthy behaviours $(Q 3$, OR: 1.15, 95\% Cl: 1.00 to 1.31 ; Q4 (highest), OR: 1.22 , $95 \% \mathrm{Cl}: 1.06$ to 1.39). Economic deprivation had a positive association with not-practising health behaviours while social deprivation had a negative association.

Conclusion These findings imply that community deprivation levels may influence individual health behaviours. Accordingly, there is a need for enforcing the role of primary healthcare centres in encouraging a healthy lifestyle among the residents in their communities, developing national health policy guidelines for health equity and providing financial help to people experiencing community deprivation.

\section{INTRODUCTION}

According to WHO, health has been defined as 'a complete physical, mental and social wellbeing, and not merely the absence of disease or infirmity." There are many factors that sustain health, with health behaviour being one of the essential ones. Health behaviours include practices such as avoiding smoking and consuming alcohol, and exercising regularly. When it comes to health maintenance, people can practice health behaviours
Strengths and limitations of this study

- This study was conducted using a large sample data, hence its results may be considered to be representative of South Korea.

- We used multilevel logistic analysis for determining the relationship between community deprivation and practising health behaviour to consider individuallevel and community-level factors simultaneously.

- Community deprivation scale used in this study has been developed considering the South Korean society, it may need to be modified to suit the sociocultural context of other countries.

and reduce the risk of diseases. ${ }^{23}$ On the other hand, an unhealthy lifestyle leads to unhealthy consequences such as cardiovascular diseases or increase in morbidity and mortality. ${ }^{4}$ Health is affected not only by physical conditions and activities, but also by the surrounding environment. ${ }^{6}$ It is well known that regional gaps in socioeconomic factors also result in health demerits. ${ }^{7-11}$

One of the most representative indicators reflecting regional disparity is the community deprivation index. It is a measurement of socioeconomic deprivation for a geographical area, and generally uses census variables. This index has been developed in various ways in multiple countries. ${ }^{12-15}$ It is also widely used in health research to establish whether relationships are associated with deprivation, as universal health coverage is one of the primary goals of the WHO. ${ }^{16}$ Health equities are also emphasised in the Sustainable Development Goals of the United Nations Organization. $^{17}$

Studies on differences in health status due to community deprivation have been actively conducted in many countries. A previous study showed that neighbourhood deprivation in urban areas had an association with 
unmet needs; however, this was not true for rural areas. ${ }^{18}$ Another study found a positive relationship between physical and mental symptoms and community deprivation after adjusting the size of the areas. ${ }^{19}$ Several studies have also revealed the relationship between a community's socioeconomic level and its health behaviours through a multilevel analysis. ${ }^{20-23}$ However, few studies have used the community deprivation index and classified community deprivation into economic and social deprivation, while studying the relationship between deprivation and health behaviours.

Based on the results of the previous studies, we hypothesised that the community deprivation index will have a positive relationship with poor health behaviours. Therefore, the objective of this study was to find the association between community deprivation index and not-practising health behaviours. In addition, we classified the components of the community deprivation index into economic and social deprivation to determine which deprivation is related to not-practising health behaviours.

\section{METHODS}

\section{Study population}

We used data from the Korea Community Health Survey (KCHS), which was carried out in 2015. This survey has been conducted annually by the Korean Centers for Disease Control and Prevention for adults aged 19 years or older since 2008 to establish and evaluate regional health plans, and standardise the survey performance system to produce comparable regional health statistics. ${ }^{24}$ The KCHS data used in this study included 198 questions across 19 fields including health behaviours, physical activities, medical service use and social environments. The KCHS distributes samples to each public health centre and targets an average of 900 people per public health centre. The participants, who accounted for $4 \%$ of the total population in South Korea were surveyed and samples were distributed proportionally by administrative region.

The data of 228558 participants were evaluated; we excluded those who answered 'do not know', gave invalid responses to the questions, or did not answer all the questions included in this study $(\mathrm{n}=4006)$. Finally, data of 224552 participants (100998 men, 123554 women) were analysed in the study.

\section{Variables}

To define health behaviours, we combined three variables suggested by the KCHS survey: no smoking, not belonging to the high-risk drinking group and walking frequently. No smoking was reflected when a participant was not smoking at the time of investigation and had experienced a ' 0 ' pack-year. Pack-year is a method of measuring the number of cigarettes a person has smoked; it is calculated by multiplying the number of packs of cigarette smoked per day by the number of years of continued smoking. We combined these two indicators to assess the exact status of smoking for each participant. Not belonging to the highrisk drinking group was defined as being a non-drinker, or drinking under five shots (for women) or under seven shots (for men) in a single sitting and consuming alcohol less than once per week. Walking frequently was defined as walking for over 30 min daily more than 5 days in the last week. Participants who met all three of these conditions were categorised into the practising-healthbehaviour group, while those who failed to meet one or over of the above conditions were categorised into the not-practising-health-behaviour group.

The community deprivation index is a measure of the influence of socioeconomic status at the regional level. The index used in this study was developed by the Korea Institute for Health and Social Affairs which is the national research institution in South Korea. The index was developed based on data from $10 \%$ of the 2015 population census in Korea. ${ }^{15}$ It is composed of nine indicators and is further classified into economic and social deprivation according to results of factor analysis. ${ }^{25}$ Economic deprivation is composed of low socioeconomic level, poor quality of housing, low educational level and the number of elder people, while social deprivation is composed of not owning a car, the portion of divorced or bereaved, the number of one-person households, female householder, and not living in an apartment. Each variable was calculated at the municipal level of Si (city), Gun (county) and $\mathrm{Gu}$ (borough) using z-scores and all the values were combined. ${ }^{15}$ Then we categorised the index into four quartiles: quartile 1 (Q1) was reflective of the lowest level of community deprivation, while quartile 4 (Q4) was reflective of the highest level (Q1 $<6.52$, $-6.52 \leq \mathrm{Q} 2<-1.24$ to $-1.24 \leq \mathrm{Q} 3<5.37, \mathrm{Q} 4>5.37)$. Since the KCHS survey was conducted in 254 public health

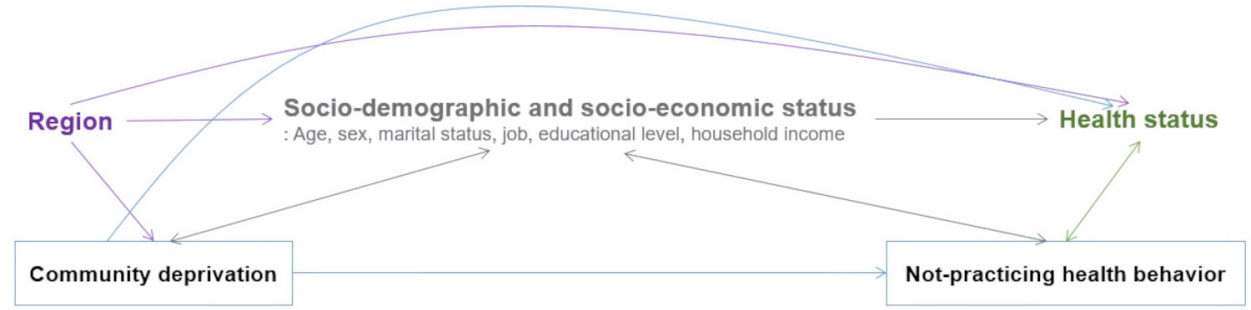

Figure 1 Directed Acyclic Graph representing the relationship between community deprivation and not-practising health behaviours. 
Table 1 General characteristics of the study population

Practising health behaviours*

Total

Variables

Total $(n=224552)$

Community level

\section{Region}

Metropolitan
Urban
Rural

Community Deprivation Index

Quartile 1 (lowest)

Quartile 2

Quartile 3

Quartile 4 (highest)

Individual level

Age (years)

$19-29$
$30-39$
$40-49$
$50-59$
$\geq 60$
Sex

Women

62063

64034

98455

27.6

28.5

23346

43.8

18616

25544

56554

54983

56097

56918

25.2

17946

24.5

17897

25.0

16356

25.3

15307

24323

32006

10.8

41235

44618

82370

14.3

18.4

19.9

36.7

100998

123554

45.0

55.0

153408

71144

68.3

31.7

43391

29412

70032

81717

19.3

13.1

12199

8693

31.2

18065

Inoccupation

36.4

28549

81205

64154

79193

36.2

28.6

25223

High school

College or over

$79193 \quad 35.3$

35.3

17838

24445

48532

21.6

79827

35.5

61005

27.2

35188

15.7

114557
53022
56973

114557
53022
56973
Practising exercise

Obesity status (BMI)‡

Underweight and Normal range

Overweight

Obese

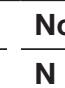

$P$ value

$157046 \quad 69.9$

$<0.0001$

$\begin{array}{ll}38717 & 62.4 \\ 45418 & 70.9 \\ 72911 & 74.1\end{array}$

$<0.0001$

$38608 \quad 68.3$

$37086 \quad 67.4$

$39741 \quad 70.8$

$\begin{array}{lll}26.9 & 41611 & 73.1\end{array}$

$\begin{array}{rrrr}8950 & 36.8 & 15373 & 63.2 \\ 7903 & 24.7 & 24103 & 75.3 \\ 10152 & 24.6 & 31083 & 75.4 \\ 13158 & 29.5 & 31460 & 70.5 \\ 27343 & 33.2 & 55027 & 66.8\end{array}$

$<0.0001$

$<0.0001$

$<0.0001$

$<0.0001$

\begin{tabular}{ll}
31192 & 71.9 \\
\hline 20719 & 70.4 \\
51967 & 74.2 \\
53168 & 65.1
\end{tabular}

$55982 \quad 68.9$

$46316 \quad 72.2$

$54748 \quad 69.1$

$<0.0001$

\begin{tabular}{llll}
14523 & 29.9 & 34009 & 70.1 \\
24045 & 30.1 & 55782 & 69.9 \\
17883 & 29.3 & 43122 & 70.7 \\
11055 & 31.4 & 24133 & 68.6 \\
\hline 35994 & 31.4 & 78563 & 68.6 \\
16109 & 30.4 & 36913 & 69.6 \\
15403 & 27.0 & 41570 & 73.0
\end{tabular}

$<0.0001$

\begin{tabular}{lllll}
21.6 & 14523 & 29.9 & 34009 & 70.1 \\
35.5 & 24045 & 30.1 & 55782 & 69.9 \\
27.2 & 17883 & 29.3 & 43122 & 70.7 \\
15.7 & 11055 & 31.4 & 24133 & 68.6 \\
\hline 51.0 & 35994 & 31.4 & 78563 & 68.6 \\
23.6 & 16109 & 30.4 & 36913 & 69.6 \\
25.4 & 15403 & 27.0 & 41570 & 73.0
\end{tabular}




\begin{tabular}{|c|c|c|c|c|c|c|c|}
\hline \multirow{3}{*}{ Variables } & \multicolumn{7}{|c|}{ Practising health behaviours* } \\
\hline & \multicolumn{7}{|l|}{ Total } \\
\hline & \multicolumn{2}{|l|}{ Total } & \multicolumn{2}{|l|}{ Yes } & \multicolumn{2}{|l|}{ No } & $P$ value \\
\hline Moderate or over & 51273 & 22.8 & 18734 & 36.5 & 32539 & 63.5 & \\
\hline No & 173279 & 77.2 & 48772 & 28.1 & 124507 & 71.9 & \\
\hline 0 & 135133 & 60.2 & 39971 & 29.6 & 95162 & 70.4 & \\
\hline 1 & 50076 & 22.3 & 15360 & 30.7 & 34716 & 69.3 & \\
\hline$\geq 2$ & 39343 & 17.5 & 12175 & 30.9 & 27168 & 69.1 & \\
\hline Perceived health status & & & & & & & $<0.0001$ \\
\hline Good & 83533 & 37.2 & 27089 & 32.4 & 56444 & 67.6 & \\
\hline Less & 166884 & 74.3 & 52703 & 31.6 & 114181 & 68.4 & \\
\hline
\end{tabular}

Inoccupation group includes housewives.

*Those who were classified under health behaviours group met all of three conditions: not smoking, not in high-risk drinking group and walking for 30 min over 5 days per week.

†The three groups (white, pink, blue) were based on the International Standard Classification Occupations codes. ¥BMI/obesity status defined by BMI based on the 2018 Clinical Practice Guidelines for Overweight and Obesity in Korea.

$\S$ Comorbid diseases included hypertension, diabetes mellitus, hyperlipidaemia and arthritis. The number of comorbid diseases is the sum of the number of diagnosed above diseases.

$\mathrm{BMI}$, body mass index.

centres, we divided administrative areas according to the unit of the public health centre.

Other covariates were also included in the analysis as potential confounding variables. At the individual level, these variables were sex, age, marital status, occupation category, educational level, household income, body mass index, comorbidity, perceived health status and perceived stress level. At the community level, these variables were region and the community deprivation index. Region was categorised into three entities: metropolitan, urban and rural. In South Korea, the metropolitan cities have a population of over 1 million and comprise small entities referred to as 'Dong', while the other cities have a population of more than 50000 and comprise smaller entities reffered to as 'Dong', 'Eup' and 'Myeon'. A 'Dong' is named assigned to a small unit in an urban area, an 'Eup' has a population of over 20 000, and a 'Myeon' is the smallest unit of these three. We defined 'Dongs' in the metropolitan cities as metropolitan regions, 'Dongs' in the other cities as the urban regions; further, the rural regions included 'Eups' and 'Myeons'. The variable of occupation was categorised according to the Korean version of the Standard Classification of Occupations, based on the International Standard Classification of Occupations by the International Labour Organization. We recategorised occupations into four categories: white (office work), pink (sales and service), blue (agriculture, forestry, fishery and armed forces) and inoccupation (those with no jobs, housewives and students). Comorbidities included in the study were hypertension, diabetes mellitus, hyperlipidemia and arthritis, and we calculated the number of comorbid diseases that a person had simultaneously.

The theorised relationship between community deprivation, not-practising health behaviours, and other covariates are represented through a Directed Acyclic Graph (DAG) (figure 1). In this DAG, all covariates are potential confounders of the association between community deprivation and not-practising health behaviours.

\section{Statistical analysis}

The $\chi^{2}$ test was used to assess for significant differences in all the covariates between those who practised health behaviours and those who did not. Differences were considered statistically significant at $p<0.05$. We also conducted multilevel logistic regression (participants nested within communities) through hierarchical generalised linear models, because the outcome variable was categorical and non-normally distributed. The analysis used in this study was based on the conceptual framework proposed by Ene $e t$ al. ${ }^{26}$

We established three models for the analysis. The first model, model 1, was a null model, which meant that it did not include any variables. This model was used to calculate the intraclass correlation coefficient (ICC), which measures how much variation in the outcome variable 
Table 2 ORs for community deprivation and not-practising health behaviours using multilevel

Not-practising health behaviours*

Total

Variables

Model 1 (Null)

Model 2 OR (95\% Cl)

Model 3 OR $(95 \% \mathrm{Cl}) \dagger$

Fixed effects

Intercept (SE)

$0.87 \ddagger(0.03)$

$0.48 \ddagger(0.04)$

$0.03 \ddagger(0.07)$

Community level

Region

$\begin{array}{ll}\text { Metropolitan } & 1.00 \\ \text { Urban } & 1.57 \text { (1.41 to } 1.75) \\ \text { Rural } & 1.73(1.55 \text { to } 1.93)\end{array}$

Community Deprivation Index

$\begin{array}{ll}\text { Quartile } 1 \text { (lowest) } & 1.00 \\ \text { Quartile } 2 & 1.02 \text { (0.89 to } 1.17) \\ \text { Quartile 3 } & 1.15 \text { (1.00 to } 1.31) \\ \text { Quartile } 4 \text { (highest) } & 1.22 \text { (1.06 to } 1.39 \text { ) }\end{array}$

Individual level

Age (years)

\begin{tabular}{|c|c|c|}
\hline $19-29$ & 1.00 & 1.00 \\
\hline 30-39 & 1.82 (1.75 to 1.90$)$ & $1.82(1.74$ to 1.89$)$ \\
\hline $40-49$ & 1.75 (1.67 to 1.82$)$ & 1.74 (1.67 to 1.82$)$ \\
\hline $50-59$ & 1.23 (1.18 to 1.28$)$ & 1.23 (1.18 to 1.28$)$ \\
\hline$\geq 60$ & 0.87 (0.83 to 0.91$)$ & 0.86 (0.83 to 0.90$)$ \\
\hline \multicolumn{3}{|l|}{ Sex } \\
\hline Men & 1.00 & 1.00 \\
\hline Women & $0.48(0.47$ to 0.49$)$ & 0.48 (0.47 to 0.49$)$ \\
\hline \multicolumn{3}{|l|}{ Marital status } \\
\hline Living with spouse & 1.00 & 1.00 \\
\hline Living without spouse & 1.18 (1.15 to 1.21$)$ & $1.18(1.15$ to 1.21$)$ \\
\hline \multicolumn{3}{|l|}{ Occupational categories§ } \\
\hline White & 1.00 & 1.00 \\
\hline Pink & 0.98 (0.94 to 1.01$)$ & 0.97 (0.94 to 1.01$)$ \\
\hline Blue & 0.98 (0.95 to 1.02$)$ & 0.98 (0.94 to 1.01$)$ \\
\hline Inoccupation & 0.89 (0.86 to 0.92$)$ & 0.89 (0.86 to 0.92$)$ \\
\hline \multicolumn{3}{|l|}{ Educational level } \\
\hline Middle school or less & 1.27 (1.22 to 1.31$)$ & 1.26 (1.21 to 1.30$)$ \\
\hline High school & $1.16(1.13$ to 1.20$)$ & 1.16 (1.13 to 1.19$)$ \\
\hline College or over & 1.00 & 1.00 \\
\hline \multicolumn{3}{|l|}{ Household income } \\
\hline Low & 0.99 (0.95 to 1.03$)$ & 0.98 (0.95 to 1.02$)$ \\
\hline Mid-low & 0.94 (0.91 to 0.97$)$ & 0.93 (0.90 to 0.96$)$ \\
\hline Mid-high & 0.98 (0.95 to 1.01$)$ & 0.98 (0.95 to 1.01$)$ \\
\hline High & 1.00 & 1.00 \\
\hline \multicolumn{3}{|l|}{ Obesity status (BMI)ף } \\
\hline Underweight and normal range & 1.00 & 1.00 \\
\hline Overweight & 0.95 (0.93 to 0.97 ) & 0.95 (0.93 to 0.97 ) \\
\hline Obese & 1.04 (1.02 to 1.07$)$ & 1.04 (1.02 to 1.07$)$ \\
\hline
\end{tabular}

Continued 
Table 2 Continued

\begin{tabular}{|c|c|c|c|}
\hline \multirow[b]{3}{*}{ Variables } & \multicolumn{3}{|c|}{ Not-practising health behaviours* } \\
\hline & \multicolumn{3}{|l|}{ Total } \\
\hline & Model 1 (Null) & Model 2 OR $(95 \% \mathrm{Cl})$ & Model 3 OR $(95 \% \mathrm{Cl}) \dagger$ \\
\hline \multicolumn{4}{|l|}{ Practising exercise } \\
\hline Moderate or over & & 1.00 & 1.00 \\
\hline No & & 1.62 (1.59 to 1.66$)$ & 1.62 (1.59 to 1.66$)$ \\
\hline \multicolumn{4}{|c|}{ The no of comorbid diseases ${ }^{\star *}$} \\
\hline 0 & & 1.00 & 1.00 \\
\hline 1 & & 0.99 (0.96 to 1.01$)$ & 0.98 (0.96 to 1.01$)$ \\
\hline$\geq 2$ & & 1.06 (1.03 to 1.09$)$ & 1.06 (1.03 to 1.09$)$ \\
\hline \multicolumn{4}{|l|}{ Perceived health status } \\
\hline Good & & 1.00 & 1.00 \\
\hline Bad & & $1.23(1.20$ to 1.26$)$ & $1.23(1.21$ to 1.26$)$ \\
\hline \multicolumn{4}{|l|}{ Perceived stress } \\
\hline Much & & $1.31(1.28$ to 1.34$)$ & 1.31 (1.28 to 1.34$)$ \\
\hline Less & & 1.00 & 1.00 \\
\hline \multicolumn{4}{|l|}{ Error variance } \\
\hline Level-2 intercept (SE) & $0.18 \ddagger(0.02)$ & $0.20 \ddagger(0.02)$ & $0.13 \ddagger(0.01)$ \\
\hline \multicolumn{4}{|l|}{ Model fit } \\
\hline$-2 \mathrm{LL}$ & 267225.3 & 256614.4 & 256514.9 \\
\hline Pearson $\chi^{2} / D F$ & 1.00 & 1.00 & 1.00 \\
\hline
\end{tabular}

*Those who were classified under the practising health behaviours group met all of three conditions: not present smoking, not in high-risk drinking group and walking for 30 min over 5 days per week.

†Best fitting model.

$\ddagger P<0.05$; intraclass correlation coefficient: $0.05289(<0.0001)$.

$\S$ Three groups (white, pink, blue) based on the International Standard Classification Occupations codes. Inoccupation group includes housewives.

IBMI/obesity status defined by BMI based on the 2018 Clinical Practice Guidelines for Overweight and Obesity in Korea.

${ }^{* *}$ Comorbid diseases included hypertension, diabetes mellitus, hyperlipidaemia and arthritis. The number of comorbid diseasese is the sum of the number of diagnosed above diseases.

BMI, body mass index.

remains between level-two units. The following equation was used for calculating ICC:

$$
I C C=\frac{\tau_{00}}{\tau_{00}+\frac{\pi^{2}}{3}}
$$

$\tau_{00}$ is the community level variance and $\frac{\pi^{2}}{3}$ corresponds to individual level variance, because this study has a dichotomous outcome variable.

The second model, model 2, included model 1 and the variables at the individual level. The results of this model indicated the relationship between the individual variables and the outcome. The third model, model 3, was the final model; it included model 2 and variables at the community level. The results of this model indicated the relationship between the community variables and the outcome. The results were reported using ORs and CIs. All statistical analyses were performed using SAS software (V.9.4, SAS Institute=).

\section{Patient and public involvement}

No patient involved.

\section{RESULTS}

Table 1 shows the general characteristics of the study population. Among the 224552 study participants, 157046 (69.9\%) participants did not practice at least one of the health behaviours. A total of 244 administrative areas were included in this study; the percentage of rural, urban, and metropolitan areas was $43.8 \%, 28.5 \%$ and $27.6 \%$, respectively,

The ORs for factors associated with not-practising health behaviours were determined using multilevel logistic regression analysis and are shown in table 2 . The ICC value was 0.05289 , indicating that $5.3 \%$ of the variability in the rate of not-practising health behaviours can be accounted for by communities, and that the odds of not-practising health behaviours vary significantly among community levels. The percentage change of variance was $27.8 \%((0.18-0.13) / 0.18 \times 100)$ and the $\log$ likelihood ratio was 256514.9 , indicating that model 3 was the best fitting model in this study. In model 3, a higher level of deprivation index was significantly associated with higher 
Table 3 Subgroup analysis of not-practising health behaviours by interesting variable*

\begin{tabular}{ll}
\hline Variables & $\begin{array}{l}\text { Not-practising health } \\
\text { behaviourst }\end{array}$ \\
\cline { 2 - 2 } & OR (95\% Cl) \\
\hline $\begin{array}{l}\text { Economic Deprivation Index } \\
\text { Quartile 1 (lowest) }\end{array}$ & 1.00 \\
Quartile 2 & $1.27(1.12$ to 1.45$)$ \\
Quartile 3 & $1.34(1.15$ to 1.57$)$ \\
$\quad$ Quartile 4 (highest) & $1.80(1.46$ to 2.20$)$ \\
\hline Social Deprivation Index & \\
\hline Quartile 1 (lowest) & 1.00 \\
\hline Quartile 2 & $0.93(0.81$ to 1.07$)$ \\
\hline Quartile 3 & $0.87(0.75$ to 1.01$)$ \\
\hline Quartile 4 (highest) & $0.81(0.67$ to 0.98$)$ \\
\hline
\end{tabular}

*Multilevel logistic analysis adjusted for variables including age, marital status, occupation, household income, BMI, the number of chronic diseases, perceived health status, perceived stress and region.

†Those who were classified under the practising health behaviours group met all of three conditions: not present smoking, not in highrisk drinking group, and walking for 30 min over 5 days per week. BMI, body mass index.

odds of not-practising health behaviours (Q3, OR: 1.15, $95 \%$ CI: 1.00 to 1.31 ; Q4, OR: $1.22,95 \%$ CI: 1.06 to 1.39$)$. Moreover, living in rural areas was most significantly associated with not-practising health behaviours (urban, OR: $1.57,95 \%$ CI: 1.41 to 1.75 ; rural, OR: $1.73,95 \%$ CI: 1.55 to 1.93$)$. Individual level variables associated with not-practising health behaviours were: ages $30-59$ years, living without a spouse, having completed only high school or less, obesity, two or more comorbid diseases, bad perceived health status, and high perceived stress. In contrast, individual variables found to have a positive association with practising health behaviours were: ages 60 years and above, being a woman, not being professionally employed, having mid-low household income and being overweight.

Table 3 presents the subgroup analysis of the community deprivation index. Results in this table were adjusted for all the variables that we used in this study. The results showed that economic deprivation was more associated with not-practising health behaviours than social deprivation. Moreover, the higher the economic deprivation, the greater was the association with not-practising health behaviours (Q2, OR: $1.27,95 \%$ CI: 1.12 to 1.45 ; Q3, OR: 1.34, $95 \%$ CI: 1.15 to 1.57 ; Q4, OR: $1.80,95 \%$ CI: 1.46 to 2.20). Interestingly, in the social deprivation index, the highest level of social deprivation showed greater association with practising health behaviours than the other levels and the OR for this association was significant $(\mathrm{Q} 4$, OR: $0.81,95 \%$ CI: 0.67 to 0.98 ).

Table 4 shows the combined effect of community deprivation and other independent variables. The difference in the community deprivation index between the lowest and the highest quartile was greater for women than for men. A similar tendency was seen in those living with a spouse; not professionally employed; having completed middle school or less, or college and over; and having low or high income.

\section{DISCUSSION}

This study was designed to determine the association between community deprivation level and health behaviours using multilevel logistic analysis. The primary outcome of the study was the association found between higher community deprivation level and not-practising health behaviours; these results were significant in Q3 and Q4 of community deprivation. After classifying community deprivation into economic and social deprivation, we found a positive relationship between economic deprivation and poor health behaviours, and a negative relationship between social deprivation and poor health behaviours.

Although the relationships between community deprivation and each variable of health behaviours were not significantly associated in this study (see online supplemental table S1), previous studies have found positive relationships between each of these variables. ${ }^{21-2327}$ These studies have also evaluated regional and environmental effects among individuals. Some places can influence poor health behaviours even in areas with lower community deprivation as compared with areas with higher community deprivation.

Several studies support this study's hypothesis. A metaanalysis confirmed that the greater the number of physical facilities in one's surroundings, more is the amount of physical activity performed by people. ${ }^{28}$ Furthermore, people who live in deprived neighbourhoods and have peers in their surroundings are more prone to being heavy drinkers than those living in non-deprived neighbourhoods. ${ }^{23}$ The behaviour of smoking is particularly affected by the surrounding environment, and a study has determined a difference in the degree to which people are affected by the surrounding environment depending on the socioeconomic level of the area in which they live. ${ }^{20}$

Meanwhile, this study obtained different results in comparison to previous studies. The results highlight the difference between material and social deprivation in terms of health; the material index can be said to be a more accurate estimate of estimating variations in health inequality within an urban area. ${ }^{29}$ Another previous study focused on the influence of material difference on health inequality. ${ }^{30}$ Since it is hard to differentiate economic from social deprivation, it is necessary to improve both conditions to achieve health equity. ${ }^{31}$ However, people with high economic status are more likely to practice health behaviours and this could enable social participation. ${ }^{32}$ Thus, it can be suggested that financial support is needed to overcome health inequality. 
Table 4 Subgroup analysis of not-practising health behaviours by independent variables*

\begin{tabular}{|c|c|c|c|c|}
\hline \multirow[b]{4}{*}{ Variables } & \multicolumn{4}{|c|}{ Not-practising health behaviours $\dagger$} \\
\hline & \multicolumn{4}{|c|}{ Community Deprivation Index } \\
\hline & Quartile 1 (lowest) & Quartile 2 & Quartile 3 & Quartile 4 (highest) \\
\hline & OR & OR $(95 \% \mathrm{Cl})$ & OR $(95 \% \mathrm{Cl})$ & OR $(95 \% \mathrm{Cl})$ \\
\hline \multicolumn{5}{|l|}{ Age (years) } \\
\hline 19-29 & 1.00 & $0.96(0.83$ to 1.10$)$ & 1.04 (0.90 to 1.21$)$ & $1.06(0.90$ to 1.25$)$ \\
\hline 30-39 & 1.00 & 1.14 (0.98 to 1.32$)$ & 1.27 (1.10 to 1.48$)$ & $1.46(1.23$ to 1.73$)$ \\
\hline $40-49$ & 1.00 & $1.02(0.88$ to 1.20$)$ & 1.21 (1.04 to 1.42$)$ & $1.24(1.05$ to 1.47$)$ \\
\hline $50-59$ & 1.00 & 0.94 (0.81 to 1.09$)$ & 1.06 (0.91 to 1.23$)$ & $1.12(0.96$ to 1.31$)$ \\
\hline$\geq 60$ & 1.00 & 1.09 (0.94 to 1.26$)$ & $1.18(1.03$ to 1.36$)$ & $1.23(1.06$ to 1.41$)$ \\
\hline \multicolumn{5}{|l|}{ Sex } \\
\hline Men & 1.00 & 0.99 (0.87 to 1.12$)$ & 1.12 (0.99 to 1.27$)$ & 1.17 (1.03 to 1.34$)$ \\
\hline Women & 1.00 & 1.06 (0.91 to 1.23$)$ & 1.18 (1.02 to 1.36$)$ & 1.27 (1.09 to 1.47$)$ \\
\hline \multicolumn{5}{|l|}{ Marital status } \\
\hline Living with spouse & 1.00 & 1.03 (0.90 to 1.19$)$ & 1.18 (1.03 to 1.35$)$ & $1.23(1.07$ to 1.42$)$ \\
\hline Living without spouse & 1.00 & 1.02 (0.89 to 1.17$)$ & 1.10 (0.96 to 1.26$)$ & 1.20 (1.04 to 1.38$)$ \\
\hline \multicolumn{5}{|l|}{ Occupational categoriesł } \\
\hline White & 1.00 & $1.00(0.86$ to 1.15$)$ & 1.12 (0.97 to 1.30$)$ & 1.15 (0.98 to 1.35$)$ \\
\hline Pink & 1.00 & 1.04 (0.89 to 1.21$)$ & 1.15 (0.98 to 1.34$)$ & $1.13(0.96$ to 1.34$)$ \\
\hline Blue & 1.00 & 0.99 (0.83 to 1.17$)$ & 1.17 (0.98 to 1.38$)$ & 1.31 (1.10 to 1.55$)$ \\
\hline Inoccupation & 1.00 & 1.07 (0.95 to 1.21$)$ & 1.15 (1.02 to 1.30$)$ & $1.19(1.05$ to 1.35$)$ \\
\hline \multicolumn{5}{|l|}{ Educational level } \\
\hline Middle school or less & 1.00 & 1.01 (0.87 to 1.18$)$ & 1.16 (1.00 to 1.36$)$ & 1.24 (1.06 to 1.44$)$ \\
\hline High school & 1.00 & 1.01 (0.87 to 1.16$)$ & 1.09 (0.94 to 1.25$)$ & 1.12 (0.96 to 1.29$)$ \\
\hline College or over & 1.00 & 1.05 (0.92 to 1.18$)$ & 1.16 (1.02 to 1.31$)$ & 1.19 (1.04 to 1.36$)$ \\
\hline \multicolumn{5}{|l|}{ Household income } \\
\hline Low & 1.00 & 1.06 (0.90 to 1.23$)$ & 1.17 (1.00 to 1.36$)$ & 1.30 (1.11 to 1.52$)$ \\
\hline Mid-low & 1.00 & 1.01 (0.88 to 1.16$)$ & 1.14 (0.99 to 1.31$)$ & 1.17 (1.01 to 1.35$)$ \\
\hline Mid-high & 1.00 & 1.02 (0.88 to 1.18$)$ & 1.13 (0.98 to 1.31$)$ & 1.15 (0.99 to 1.34$)$ \\
\hline High & 1.00 & 1.04 (0.89 to 1.22$)$ & 1.22 (1.03 to 1.44$)$ & $1.20(1.00$ to 1.44$)$ \\
\hline
\end{tabular}

Inoccupation group includes students, housewives and those with no jobs.

*Multilevel logistic analysis adjusted for variables including age, marital status, occupation, household income, BMI, the number of chronic diseases, perceived health status, perceived stress and region.

†Those who were classified under the practising health behaviours group met all of three conditions: not present smoking, not in high-risk drinking group, and walking for 30 min over 5 days per week.

$\ddagger$ Three groups (white, pink, blue) were based on the International Standard Classification Occupations codes.

BMI, body mass index.

Another finding was the influence of sex in determining the extent to which community deprivation related to health behaviours. This study found a greater difference in the association of bad health behaviours between women living in the more deprived areas and less deprived areas than that between men from similar areas. A previous study focusing on the association between neighbourhood differences in self-rated health supports this result. ${ }^{33}$ In addition, women are more susceptible to the effect of neighbourhood socioeconomic deprivation than men. Women who live in socioeconomically deprived areas are more likely to be stressed and less likely to practise health behaviours. ${ }^{34} 35$ As seen in our results, women were more likely to practice health behaviours and were more vulnerable to deprived environments compared with men.

While the findings of the study shed important light on how individual and community-level variables relate to poor health behaviours, this study has several limitations. First, factors of health behaviour were self-reported. As such, the participants had to respond based on their memory, and their responses might not have been accurate. Second, we considered only three factors of health behaviour. Other health behaviours such as physical 
activity and diet habits may also be affected by community deprivation. Thus, we adjusted them as covariates in this study. Third, because of a lack of questions, we did not consider the intensity or purpose of walking in this study. Fourth, since this is a cross-sectional study, we did not consider any change in the practice of health behaviour and causal relationships. Last, since the community deprivation scale used in this study has been developed considering the South Korean society, ${ }^{15}$ it may need to be modified to suit the sociocultural context of other countries.

Despite these limitations, our study has several strengths. First, this study was conducted using a large sample data; hence, its results may be considered to be representative of the South Korean society. Second, we analysed and found a positive association between community deprivation level and not-practising health behaviours using multilevel logistic regression to consider two-level variables, including those at the individual and community level. Thus, our results imply the influence of the community in individual health behaviours.

Based on these results, there is a need to enforce the role of primary healthcare centres in encouraging a healthy life for residents within communities, and to invest in education and awareness on the practice of health behaviour. At the national level, devoting adequate resources (eg, public sports facilities, healthcare providers or financial aids) for deprived area and developing health policies are required to achieve health equity. ${ }^{36}$ Considering that women are more affected in socioeconomically deprived areas than men, it is necessary to design customised healthcare strategies for the underprivileged (eg, elderly, single-parent families or those living in a low residential environment). Furthermore, an integrated model between the central and local administration is needed to manage people's health systematically. ${ }^{38}$ Accordingly, further research is required to construct a health model to achieve health equity, to measure the effectiveness of the input resources, and to develop policies. Moreover, longitudinal study to determine the impact of how changing the community deprivation levels might affect residents' health behaviour and health status, is warranted.

Contributors BNJ designed this study, performed statistical analysis, drafted and completed the manuscript. HMY and DWL contributed to the concept and design of the study, and provided statistical expertise and interpretation. JHJ revised the manuscript critically for important intellectual content. E-CP conceived, designed and directed this study. All authors read and approved the final manuscript.

Funding The authors have not declared a specific grant for this research from any funding agency in the public, commercial or not-for-profit sectors.

Competing interests None declared.

Patient consent for publication Not required.

Ethics approval The data is an open access dataset and did not contain any personal information on patients, therefore no ethical approval was required.

Provenance and peer review Not commissioned; externally peer reviewed.

Data availability statement The data that support the findings of this study are openly available in the Korea Community Health Survey at http://chs.kdca.go.kr/.
Supplemental material This content has been supplied by the author(s). It has not been vetted by BMJ Publishing Group Limited (BMJ) and may not have been peer-reviewed. Any opinions or recommendations discussed are solely those of the author(s) and are not endorsed by BMJ. BMJ disclaims all liability and responsibility arising from any reliance placed on the content. Where the content includes any translated material, BMJ does not warrant the accuracy and reliability of the translations (including but not limited to local regulations, clinical guidelines, terminology, drug names and drug dosages), and is not responsible for any error and/or omissions arising from translation and adaptation or otherwise.

Open access This is an open access article distributed in accordance with the Creative Commons Attribution Non Commercial (CC BY-NC 4.0) license, which permits others to distribute, remix, adapt, build upon this work non-commercially, and license their derivative works on different terms, provided the original work is properly cited, appropriate credit is given, any changes made indicated, and the use is non-commercial. See: http://creativecommons.org/licenses/by-nc/4.0/.

ORCID iDs

Bich Na Jang http://orcid.org/0000-0002-4660-9044

Eun-Cheol Park http://orcid.org/0000-0002-2306-5398

\section{REFERENCES}

1 World Health Organization. Constitution of World Health Organization. Available: https://www.who.int/about/who-we-are/ constitution [Accessed 21 Jul 2020].

2 Blair SN, Cheng Y, Holder JS. Is physical activity or physical fitness more important in defining health benefits? Med Sci Sports Exerc 2001;33:S379-99.

3 Lee L-L, Arthur A, Avis M. Evaluating a community-based walking intervention for hypertensive older people in Taiwan: a randomized controlled trial. Prev Med 2007;44:160-6.

4 Ockene IS, Miller NH. Cigarette smoking, cardiovascular disease, and stroke: a statement for healthcare professionals from the American heart association. Circulation 1997;96:3243-7.

5 Laatikainen T, Manninen L, Poikolainen K, et al. Increased mortality related to heavy alcohol intake pattern. J Epidemiol Community Health 2003;57:379-84.

6 Sartorius N. The meanings of health and its promotion. Croat Med $J$ 2006;47:662-4.

7 Malmström M, Sundquist J, Johansson SE. Neighborhood environment and self-reported health status: a multilevel analysis. Am J Public Health 1999;89:1181-6.

8 Stimpson JP, Ju H, Raji MA, et al. Neighborhood deprivation and health risk behaviors in NHANES III. Am J Health Behav 2007;31:215-22.

9 Hoffman A, Holmes M. Regional differences in rural and urban mortality trends. Chapel Hill (NC) NC Rural Health Research Program; 2017. https://www.ruralhealthresearch.org/alerts/185 [Accessed 23 Jul 2020].

10 Detollenaere J, Hanssens L, Vyncke V, et al. Do we reap what we sow? exploring the association between the strength of European primary healthcare systems and inequity in unmet need. PLoS One 2017;12:e0169274.

11 Youn HM, Lee DW, Park E-C. Association between community outpatient clinic care accessibility and the uptake of diabetic retinopathy screening: a multi-level analysis. Prim Care Diabetes 2020;14:616-21.

12 Townsend P. Deprivation. J Soc Policy 1987;16:125-46.

13 Pampalon R, Hamel D, Gamache P, et al. A deprivation index for health planning in Canada. Chronic Dis Can 2009;29:178-91.

14 Salmond C, Crampton P, Sutton F. NZDep91: a New Zealand index of deprivation. Aust N Z J Public Health 1998;22:835-7.

$15 \mathrm{Kim} \mathrm{D,} \mathrm{Lee} \mathrm{S,} \mathrm{Ki} \mathrm{M.} \mathrm{Developing} \mathrm{health} \mathrm{inequalities} \mathrm{indicators} \mathrm{and}$ monitoring the status of health inequalities in Korea. Seoul Korea Institute for Health and Social Affairs; 2013: 166-79.

16 World Health Organization. Univeral health coverage. Available: https://www.who.int/news-room/fact-sheets/detail/universal-healthcoverage-(uhc) [Accessed $21 \mathrm{Jul} 2020$ ]

17 The United Nations. About the sustainable development goals. Available: https://www.un.org/sustainabledevelopment/sustainabledevelopment-goals/ [Accessed 21 Jul 2020].

18 Lee SE, Yeon M, Kim C-W, et al. Neighborhood deprivation and unmet health care needs: a multilevel analysis of older individuals in South Korea. Osong Public Health Res Perspect 2019;10:295-306.

19 Reijneveld SA, Verheij RA, de Bakker DH. The impact of area deprivation on differences in health: does the choice of the 
geographical classification matter? J Epidemiol Community Health 2000;54:306-13.

20 Adams RJ, Howard N, Tucker G, et al. Effects of area deprivation on health risks and outcomes: a multilevel, cross-sectional, Australian population study. Int J Public Health 2009;54:183-92.

21 Moore GF, Littlecott HJ. School- and family-level socioeconomic status and health behaviors: multilevel analysis of a national survey in Wales, United Kingdom. J Sch Health 2015;85:267-75.

22 Wen M, Browning CR, Cagney KA. Neighbourhood deprivation, social capital and regular exercise during adulthood: a multilevel study in Chicago. Urban Studies 2007;44:2651-71.

23 Fone DL, Farewell DM, White J, et al. Socioeconomic patterning of excess alcohol consumption and binge drinking: a cross-sectional study of multilevel associations with neighbourhood deprivation. BMJ Open 2013;3:e002337.

24 Kang YW, Ko YS, Kim YJ, et al. Korea community health survey data profiles. Osong Public Health Res Perspect 2015;6:211-7.

25 Choi D-W, Lee SA, Lee DW, et al. Effect of socioeconomic deprivation on outcomes of diabetes complications in patients with type 2 diabetes mellitus: a nationwide population-based cohort study of South Korea. BMJ Open Diab Res Care 2020;8:e000729.

26 Ene M, Leighton EA, Blue GL, Bell BA. Multilevel models for categorical data using SAS $₫$ PROC GLIMMIX: the basics SAS Global Forum; 2015. Multilevel models for categorical data using SAS $®$ PROC GLIMMIX

27 Duncan C, Jones K, Moon G. Smoking and deprivation: are there neighbourhood effects? Soc Sci Med 1999;48:497-505.

28 Humpel N, Owen N, Leslie E. Environmental factors associated with adults' participation in physical activity: a review. Am J Prev Med 2002;22:188-99.
29 Testi A, Ivaldi E. Material versus social deprivation and health: a case study of an urban area. Eur J Health Econ 2009;10:323-8.

30 Benach J, Yasui Y, Borrell C, et al. Material deprivation and leading causes of death by gender: evidence from a nationwide small area study. J Epidemiol Community Health 2001;55:239-45.

31 Marmot $\mathrm{M}$. The health gap: the challenge of an unequal world. The Lancet 2015;386:2442-4.

32 Marmot M. The influence of income on health: views of an epidemiologist. Health Aff 2002;21:31-46.

33 Stafford M, Cummins S, Macintyre S, et al. Gender differences in the associations between health and neighbourhood environment. Soc Sci Med 2005;60:1681-92.

34 Grimaud O, Lapostolle A, Berr C, et al. Gender differences in the association between socioeconomic status and subclinical atherosclerosis. PLoS One 2013;8:e80195.

35 Alves L, Silva S, Severo M, et al. Association between neighborhood deprivation and fruits and vegetables consumption and leisure-time physical activity: a cross-sectional multilevel analysis. BMC Public Health 2013;13:1-9.

36 Dover DC, Belon AP. The health equity measurement framework: a comprehensive model to measure social inequities in health. Int $J$ Equity Health 2019;18:1-12.

37 Morrin L, Britten J, Davachi S, et al. Alberta Healthy Living Program-a model for successful integration of chronic disease management services. Can J Diabetes 2013;37:254-9.

38 Jang S-nang, Lee JH, Kim C-O. Developing key indicators of health equity and strategies for reducing health disparity in national health plan. Korean Journal of Health Education and Promotion 2017;34:41-57. 